Provided for non-commercial research and education use. Not for reproduction, distribution or commercial use.

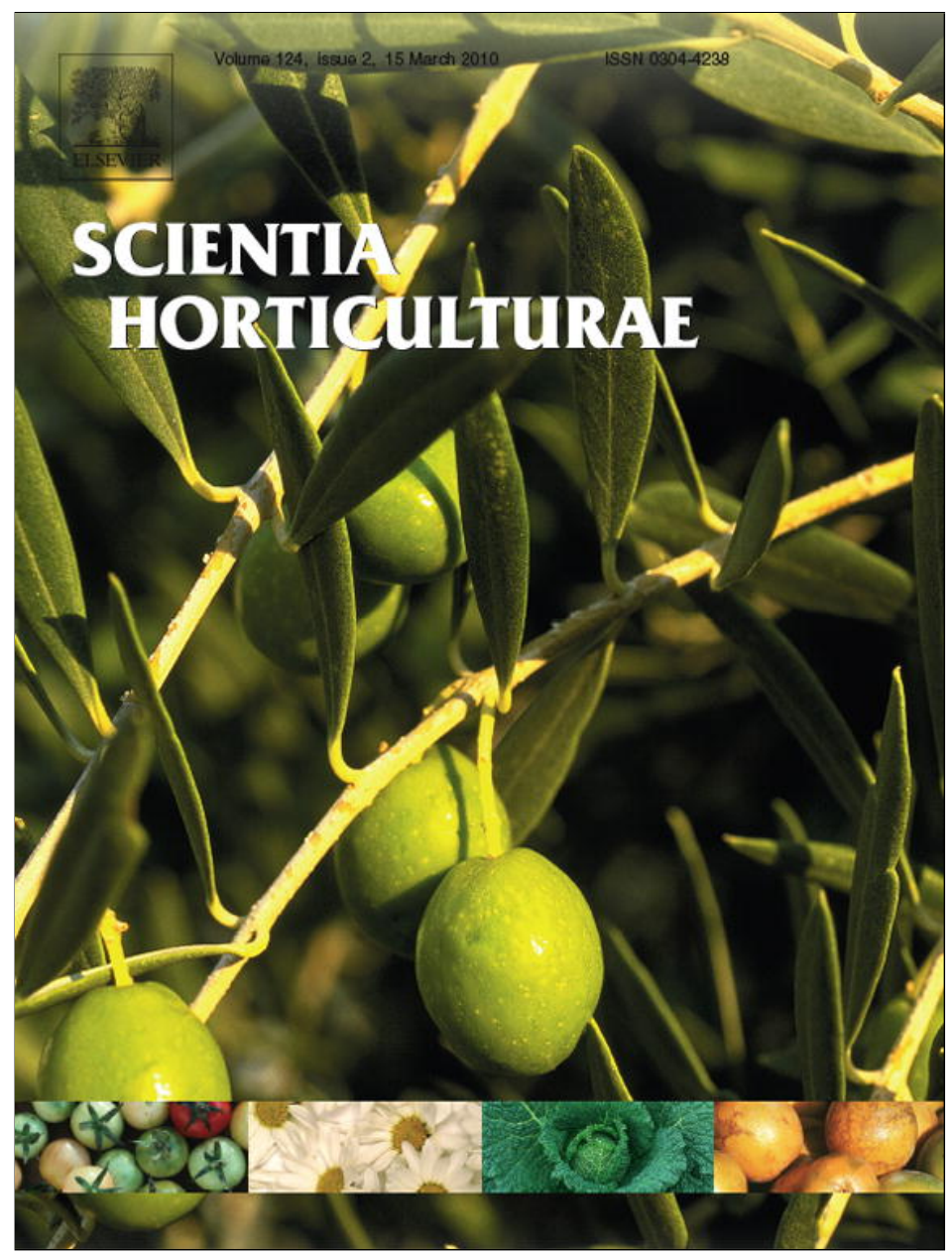

This article appeared in a journal published by Elsevier. The attached copy is furnished to the author for internal non-commercial research and education use, including for instruction at the authors institution and sharing with colleagues.

Other uses, including reproduction and distribution, or selling or licensing copies, or posting to personal, institutional or third party websites are prohibited.

In most cases authors are permitted to post their version of the article (e.g. in Word or Tex form) to their personal website or institutional repository. Authors requiring further information regarding Elsevier's archiving and manuscript policies are encouraged to visit:

http://www.elsevier.com/copyright 


\title{
Use of ISSR markers to assess genetic diversity of African edible seeded Citrullus lanatus landraces
}

\author{
Y. Djè ${ }^{\mathrm{a}, *}$, C.G. Tahi ${ }^{\mathrm{c}}$, A.I. Zoro Bi ${ }^{\mathrm{a}}$, J.-P. Baudoin ${ }^{\mathrm{b}}$, P. Bertin ${ }^{\mathrm{c}}$ \\ a Laboratoire de génétique, UFR des Sciences de la Nature, Université d'Abobo-Adjamé, 02 BP 801, Abidjan 02, Cote d'Ivoire \\ ${ }^{\mathrm{b}}$ Unité d'horticulture et phytotechnie tropicale, Faculté des Sciences Agronomiques de Gembloux, B-5030 Belgium \\ ${ }^{\mathrm{c}}$ Laboratoire d'écophysiologie et amélioration végétale, Université catholique de Louvain, Croix du Sud, 2 b11, B-1348 Louvain-la-neuve, Belgium
}

\section{A R T I C L E I N F O}

\section{Article history:}

Received 17 July 2009

Received in revised form 12 November 2009 Accepted 9 December 2009

\section{Keywords:}

ISSR

Citrullus lanatus

Genetic diversity

\begin{abstract}
A B S T R A C T
We used the twenty primers to evaluate the genetic variability of 80 individuals belonging to four accessions of edible seeded Citrullus lanatus originated from Côte d'Ivoire. Edible seeded C. lanatus, named "egusi" or "pistachio", had a great importance in nutrition in West Africa. Nevertheless, due to its neglected status no study to our knowledge has been devoted to its genetic variability using DNA markers. The twenty ISSR primers generated 258 bands among which 252 were polymorphic (97.67\%). On the whole, the bands generated revealed three types of profile sharply distinct from each other with minor differences within each type. One profile (P1) was most frequent with 65 individuals. Three accessions (NI084, NI127 and NI145) generated the three types of profile and had medium values of genetic diversity ( $G D=0.246-0.275$, respectively). On the opposite, the accession NI076 only contained individuals of the most represented type of profile (P1) and had the lowest genetic diversity $(\mathrm{GD}=0.055 \pm 0.017)$. The pairwise genetic distance between the 80 individuals varied from 0 to 0.61 . The Factorial Component Analysis and the dendrogram clearly separated the 80 individuals into three clusters corresponding to the three types of profile. The results showed that clusters were well separated from each other whereas accessions were not. Our results suggest that high number of individuals should be taken into account for sampling missions and conservation strategies because accessions were not well differentiated from each other. Local agricultural practices consisting of frequent seeds exchanges between farmers and the conservation of harvested seeds for next year culture could be one explanation.
\end{abstract}

(c) 2009 Elsevier B.V. All rights reserved.

\section{Introduction}

The Cucurbitaceae family is one of the most economically important families worldwide. It is cultivated in all parts of the world and is used in many processes. For the most commercial species, several modern varieties are cultivated in intensive cropping systems with high inputs and only the flesh is consumed crude or as soup. Many traditional cucurbitaceous species are reported in several West and Central Africa where there are cultivated by women on a great diversity of soil types and rainfall, annually, as minor crops intercropped with staple food. For these species locally called "pistachio" or "egusi", only seeds are transformed into paste for consumption (Badifu, 2001; Zoro Bi et al., 2003). These species share an important source of income for rural people. Nevertheless, due to their underused status, these locally adapted landraces have received little attention from

\footnotetext{
* Corresponding author. Tel.: +225 203042 93/22 4752 57. fax: +225 20308118 .

E-mail addresses: saticlan@yahoo.fr, boungueh@yahoo.fr (Y. Djè).
}

scientists and deciders. To preserve the genetic richness of these landraces, efforts must be direct towards the implementation of reliable collecting and conservation strategies. Such plant materials are useful to set up breeding programs for cash crops. According to Zoro Bi et al. (2006), five species of Cucurbitaceae are cultivated for seed consumption in Côte d'Ivoire. Citrullus lanatus L. Matsumura \& Nakai is one of the most important of them with respect to cultivation area, production and commercial transactions volume. This species is monoecious and naturally crosspollinated (Jaskani et al., 2005; Ellul et al., 2007) with outcrossing rate arounding 75\% (Ferreira et al., 2008). There is a need of urgent conservation program to avoid a serious depletion of the genetic richness of oilseed $C$. lanatus.

Several studies have been devoted to assess genetic variability of Cucurbitaceae based on molecular markers (Katzir et al., 1996; Levi et al., 2004; Behera et al., 2008). Among a wide range of DNA markers methods available, single sequence repeats (SSR) or microsatellites tend to be the most variable for discriminating among genotypes (Russell et al., 1997; Pejic et al., 1998). Microsatellites are widely represented in the genome but require complex methods to generate reliable markers and are highly 
Table 1

List of 20 primers, melting $\left(T_{\mathrm{m}}\right)$ and annealing $\left(T_{\mathrm{a}}\right)$ temperatures optimized for PCR amplification, percentage of polymorphic bands generated per primer and the mean PIC per primer in C. lanatus.

\begin{tabular}{|c|c|c|c|c|c|c|c|c|}
\hline \multicolumn{9}{|c|}{ Amplified fragments } \\
\hline No & Primer & Sequence $\left(5^{\prime} \rightarrow 3^{\prime}\right)$ & $T_{\mathrm{m}}\left({ }^{\circ} \mathrm{C}\right)$ & $T_{\mathrm{a}}\left({ }^{\circ} \mathrm{C}\right)$ & Total & Polymorphic fragments & Polymorphic bands (\%) & $\mathrm{PIC}_{\text {mean }}($ mean \pm s.e. $)$ \\
\hline 1 & Sola 1 & $\mathrm{BDB}-(\mathrm{ACA})_{5}$ & 50 & 51 & 15 & 15 & 100 & $0.16 \pm 0.08$ \\
\hline 2 & Sola 2 & $\mathrm{DD}-(\mathrm{CCA})_{5}$ & 56 & 55 & 10 & 9 & 90 & $0.19 \pm 0.13$ \\
\hline 3 & Sola 3 & $\mathrm{DHB}-(\mathrm{CGA})_{5}$ & 58 & 59 & 16 & 16 & 100 & $0.13 \pm 0.07$ \\
\hline 4 & Sola 4 & VHV-(GT) $)_{7}-\mathrm{G}$ & 56 & 55 & 13 & 13 & 100 & $0.22 \pm 0.06$ \\
\hline 5 & Sola 5 & $\mathrm{BDB}-(\mathrm{AC})_{7}$ & 50 & 55 & 13 & 13 & 100 & $0.18 \pm 0.13$ \\
\hline 6 & Sola 6 & $\mathrm{BDB}-(\mathrm{CAC})_{5}$ & 60 & 59 & 15 & 15 & 100 & $0.24 \pm 0.14$ \\
\hline 7 & Sola 7 & $(\mathrm{AG})_{8}-\mathrm{YT}$ & 52 & 51 & 10 & 10 & 100 & $0.21 \pm 0.06$ \\
\hline 8 & Sola 8 & $(\mathrm{GA})_{8}-\mathrm{YC}$ & 56 & 55 & 13 & 12 & 92.3 & $0.15 \pm 0.08$ \\
\hline 9 & Sola 9 & $(\mathrm{AC})_{8}-\mathrm{G}$ & 52 & 51 & 13 & 13 & 100 & $0.15 \pm 0.13$ \\
\hline 10 & Sola 10 & $(\mathrm{AC})_{8} \mathrm{YG}$ & 56 & 55 & 11 & 10 & 90.9 & $0.17 \pm 0.15$ \\
\hline 11 & Sola 11 & $\mathrm{GAG}-(\mathrm{CAA})_{5}$ & 50 & 59 & 15 & 15 & 100 & $0.19 \pm 0.11$ \\
\hline 12 & Sola 12 & CTG-(AG) $)_{8}$ & 58 & 59 & 17 & 16 & 94.11 & $0.15 \pm 0.09$ \\
\hline 13 & В 1 & $(A G)_{8}-C$ & 52 & 59 & 16 & 16 & 100 & $0.20 \pm 0.17$ \\
\hline 14 & В 3 & (GA)8-A & 50 & 55 & 12 & 12 & 100 & $0.17 \pm 0.14$ \\
\hline 15 & В 4 & $(\mathrm{GA})_{8}-\mathrm{C}$ & 52 & 51 & 13 & 12 & 92.3 & $0.19 \pm 0.11$ \\
\hline 16 & B 5 & $(\mathrm{GA})_{8}-\mathrm{T}$ & 48 & 55 & 12 & 12 & 100 & $0.22 \pm 0.06$ \\
\hline 17 & B 6 & $(\mathrm{GATG})_{4}-\mathrm{C}$ & 49 & 51 & 12 & 12 & 100 & $0.16 \pm 0.07$ \\
\hline 18 & CBTC 1 & $(A G)_{8}-T$ & 50 & 55 & 13 & 12 & 92.3 & $0.20 \pm 0.14$ \\
\hline 19 & CBTC 2 & $(A G)_{8}-G$ & 52 & 59 & 13 & 13 & 100 & $0.15 \pm 0.06$ \\
\hline 20 & P 5 & $(\mathrm{TG})_{8}-\mathrm{A}$ & 50 & 51 & 6 & 6 & 100 & $0.19 \pm 0.05$ \\
\hline Total & & & & & 258 & 252 & & \\
\hline Mean & & & & & 12.9 & 12.6 & 97.67 & $0.18 \pm 0.02$ \\
\hline
\end{tabular}

specific. A variant of microsatellites called ISSR (Inter Simple Sequence Repeat) involves the amplification of DNA region located between two microsatellites loci (Zietkiewicz et al., 1994). ISSR method combines the advantages of RAPD markers widely dispersed in species genome with high polymorphism and reliability of microsatellite. In addition, ISSR method is suitable for less known species like African edible seeded $C$. lanatus. This marker has a greater robustness in repeatability and show a high variability (Bornet and Branchard, 2001). We previously showed that ISSR could be powerful to evaluate genetic diversity of African edible seeded Cucurbitaceae (Djè et al., 2006). The objectives of the present study were: (1) to increase the number of ISSR primers available for African edible seeded landraces studies; (2) to assess genetic diversity and structure in accessions of the indigenous $C$. lanatus with a view to further develop improved strategies for collecting missions.

\section{Material and methods}

\subsection{Plant material}

Four accessions of C. lanatus L. Matsumura and Nakai conserved in the cucurbits collection of the University of Abobo-Adjamé (Abidjan, Côte d'Ivoire) were selected for this study. These accessions were collected from two agro ecological zones of Côte d'Ivoire (NI076 and NI084 from the savannah region with medium rainfall $(1200-1400 \mathrm{~mm})$ and sandy soil, NI127 and NI145 from forest region with high rainfall ( $>2000 \mathrm{~mm}$ ) and loamy soil rich in organic matter). Twenty seeds per accession were grown in a greenhouse at $25{ }^{\circ} \mathrm{C}$ and 16 h daylength. Thus, a total of eighty seeds from four accessions were analysed.

\subsection{DNA extraction and electrophoresis}

About 75-80 mg DNA from leaves of 21-day-old plants were extracted directly in Eppendorf tubes following Murray and Thompson (1980) protocol with few modifications as described by Djè et al. (2006). Briefly, leaf tissues were directly grounded in Eppendorf tubes in $500 \mu \mathrm{l}$ of cethyltrimethylammonium bromide (CTAB) extraction buffer containing 2\% CTAB, $2 \mathrm{M} \mathrm{NaCl}, 2 \% \mathrm{PVP}$, $20 \mathrm{mM}$ EDTA pH 8.2, $100 \mathrm{mM}$ Tris- $\mathrm{HCl} \mathrm{pH} 8.0$, and $1 \% \beta-$ mercaptoethanol. The extracted DNA was quantified on $0.8 \%$ agarose gel with TBE $1 \times$ buffer $(10 \times$ TBE: $108 \mathrm{~g} / 1$ Tris base, $55 \mathrm{~g} / 1$ boric acid, $8.3 \mathrm{~g} / \mathrm{l}$ EDTA $\mathrm{pH}$ 8.0) and about $60 \mathrm{ng}$ were used in amplification reactions.

Twenty primers (Eurogentec) were used in optimization process. Twelve and eight of them were $3^{\prime}$ - and 5'-anchored, respectively (Table 1 ). Eleven of these primers had been previously optimized for African edible seeded C. lanatus landraces (Djè et al., 2006). The polymerase chain reactions (PCR) were performed in a mix containing 0.2 units per reaction of Taq DNA polymerase (Eurogentec), $1 \mu$ l of PCR buffer (Eurogentec buffer system II), $0.2 \mu \mathrm{l}$ of $2 \mathrm{mM}$ dNTPs, $0.16 \mu \mathrm{l}$ of each ISSR primer, $60 \mathrm{ng}$ of extracted DNA. PCR cycling conditions were as follows: 10 min initial denaturation at $95^{\circ} \mathrm{C}, 36$ cycles of amplification [30 s at $95^{\circ} \mathrm{C}, 45 \mathrm{~s}$ at the annealing temperature $\left(T_{\mathrm{a}}\right), 2$ min elongation at $72{ }^{\circ} \mathrm{C}$ ] and final elongation of $5 \mathrm{~min}$ at $95^{\circ} \mathrm{C}$. PCR reactions were performed with a thermal cycler PTC- $100^{\mathrm{TM}}$ Gradient $96(\mathrm{MJ}$ Research, Inc.). To determine the optimal annealing temperature $\left(T_{\mathrm{a}}\right)$, an interval of $10{ }^{\circ} \mathrm{C}$ around the melting temperature $\left(T_{\mathrm{m}}\right)$ was tested. Temperatures leading to clear patterns were then repeated until the best $T_{\mathrm{a}}$ was selected for routine procedure. The reproducibility of the technique was tested by carrying out two independent PCR with one positive control sample as well as one negative control.

The result of each amplification reaction was analysed on 1.5\% agarose gel (Molecular grade II from Eurogentec) in $1 \times$ TBE (Tris Borate EDTA) buffer. A smartladder provided by Eurogentec was used as standard marker to estimate sizes of PCR products by migration distance comparison (200-10,000 bp). The gels were stained by soaking $1.4 \mu \mathrm{l}$ of ethidium bromide in $100 \mathrm{ml}$ of agarose. Electrophoresis was run for $3 \mathrm{~h}$ at $90 \mathrm{~V}$ and DNA was visualised with an UV transilluminator and analysed with a video image analyser (Biocapt, Vilbert-Lourmat, Marne-La-Vallée, France). 


\subsection{Data collection and analysis}

Only clearly and reproducible bands were scored. The percentage of reproducibility was determined by dividing the number of reproducible bands by the total number of bands observed (McGregor et al., 2000). The gels were scored for the presence (1) and absence (0) of amplification fragments using the computer program Gene Profiler V4.04 for Windows (Scanalytics, Inc.). Binary data from different primers were used to perform the analysis. The polymorphic information content (PIC) of a band was calculated according to the formula:

$\mathrm{PIC}=\sum\left[1-\left(p_{i}^{2}+a_{i}^{2}\right)\right]$

where $p_{i}$ and $a_{i}$ are the presence and absence frequencies of the $i$ th band, respectively.

A factorial correspondence analysis (FCA) based on ISSR markers were performed using the SAS statistical program. The analysis of the molecular variance AMOVA at two levels (within and between the accessions) was performed using the GenAlEx6 software (Peakall and Smouse, 2006) from the molecular data provided by ISSR markers. The genetic distances (Nei and Li, 1979) between individuals were calculated and a dendrogram was generated using the UPGMA (unweighted pair-group method with arithmetic averaging) cluster analysis with Treecon software (Van de Peer and De wachter, 1994). Bootstrap analysis was performed with a set of 20 primers to test the reliability of the tree obtained.

\section{Results}

\subsection{ISSR markers optimized and polymorphism detected}

For all of the 20 ISSR markers tested, we obtained clear and reproducible bands as showed for primer Sola 4 (Fig. 1). Nine optimal annealing temperatures $\left(T_{\mathrm{a}}\right)$ were lower and eleven higher than $T_{\mathrm{m}}$ (one degree below and from one to nine degree above $T_{\mathrm{m}}$, respectively). These temperatures could be grouped in three groups $\left(51^{\circ} \mathrm{C}, 55^{\circ} \mathrm{C}\right.$ and $\left.59^{\circ} \mathrm{C}\right)$. The 20 ISSR primers amplified a total of 258 bands resulting in an average of 12.9 bands per primer. The lowest number of bands was observed with primer P 5 (6) which was the only primer amplifying less than 10 bands. The highest number of bands was observed for primer Sola 12 (17). The molecular weight of the bands varied from $192 \mathrm{pb}$ (Sola 3) to $2015 \mathrm{pb}$ (Sola 9). Of the 258 bands amplified, 252 showed polymorphism corresponding to $97.67 \%$ of polymorphic bands. The average number of polymorphic bands per primer was 12.6. The Polymorphic Information Content (PIC) per primer ranged from 0.13 (Sola 3) to 0.24 (Sola 6), with a mean of 0.18 (Table 1).

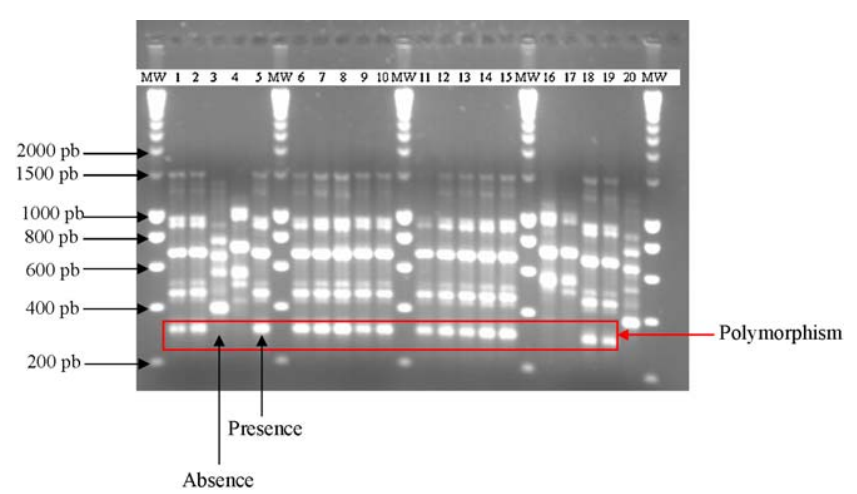

Fig. 1. Polymorphism revealed by ISSR primer Sola 4 (20 individuals of accession NI127).

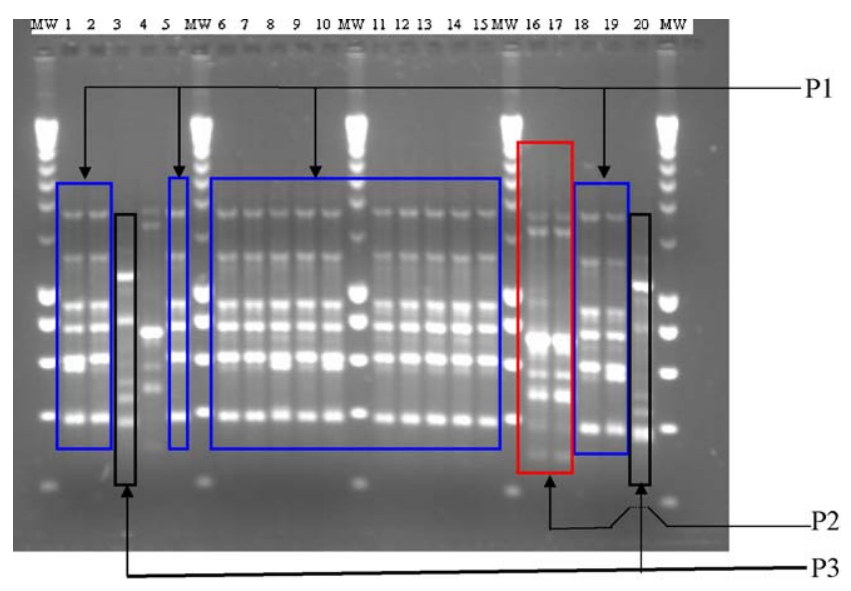

1-20: number of individuals analysed

MW: molecular weight

P1, P2, P3: different patterns observed

Fig. 2. Electrophoresis gel of 20 individuals of $C$. lanatus accession NI127 amplified with the primer Sola 4 showing the three types of profile. Lanes 1, 2, 5, 6 to 15,18 and 19: profile P1; lanes 16 and 17: profile 2; lanes 3 and 20: profile 3; lanes MW: standard molecular weight.

\subsection{Genetic diversity}

For the entire experiment on 80 individuals from the four different accessions analysed with 20 primers, three types of profiles were clearly highlighted (Fig. 2). Minor differences were revealed inside each type of profile. Three accessions (NI084, NI127 and NI145) exhibited the three types of profiles, while the accession NI076 presented only one type of profile (P1). The first two axis of the factorial component analysis (FCA) explained $59 \%$ of the total variation ( 38.29 and $20.71 \%$ of the variation, respectively

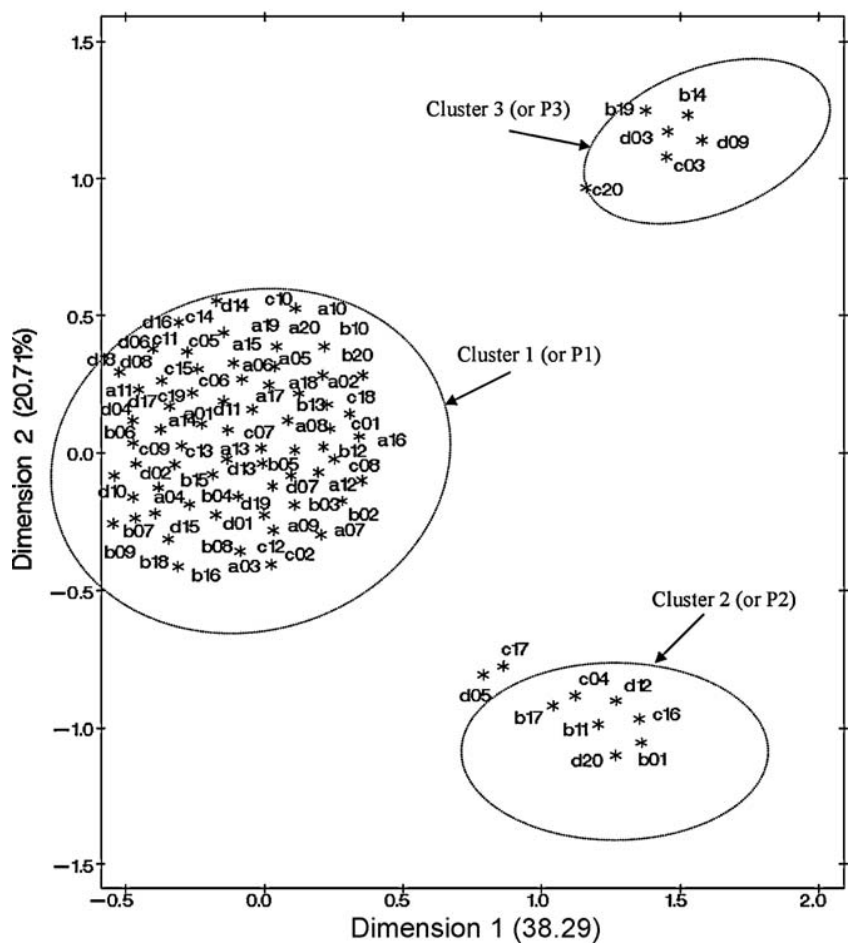

Fig. 3. Factorial Correspondence Analysis based on ISSR polymorphism of $80 \mathrm{C}$. lanatus individuals. a, b, c and d for accessions NI076, NI084, NI127 and NI145, respectively. 


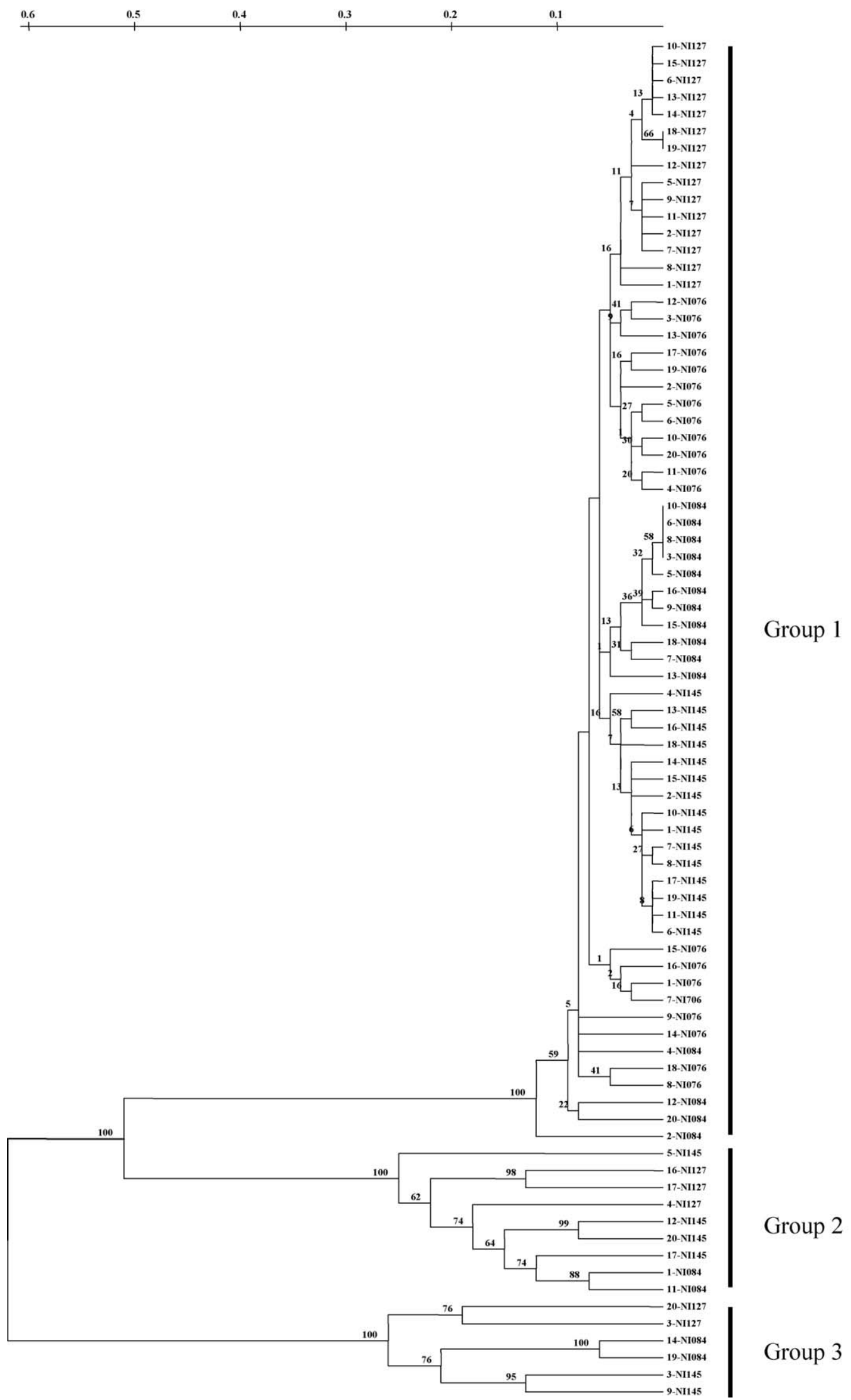

Fig. 4. UPGMA dendrogram using Nei (Nei \& Li, 1979) distance of ISSR band profiles from samples of 80 C. lanatus individuals. The scale bar on the top of figure represents the pairwise genetic distances between individuals. 
for axis 1 and 2). Three main clusters could be distinguished in FCA (Fig. 3). The first component separated clusters 2 and 3 from cluster 1 . The second axis clearly separated the three groups from each other. The first cluster contained 65 individuals belonging to the four accessions, whereas clusters 2 and 3 contained 9 and 6 individuals respectively, belonging to 3 accessions only. The dendrogram UPGMA (Fig. 4) divided the 80 individuals into 3 main clusters that clearly corresponded to the structure obtained with the FCA. The genetic structure inside the three clusters revealed a sub-clustering by accession: individuals from same accession were grouped into one or a few number of sub-clusters. This is particularly true for clusters 2 and 3 for which no superimposing was observed between individuals from different accessions. We found $83 \%$ of the variation between clusters using AMOVA $\left(F_{\mathrm{st}}=0.83, P\right.$-value $\left.<0.1\right)$, indicating that clusters were highly different from each other. The genetic distances between clusters were $0.507 \pm 0.048$ (clusters 1 and 2), $0.627 \pm 0.032$ (clusters 1 and 3 ) and $0.617 \pm 0.040$ (clusters 2 and 3 ). In contrast, the pairwise genetic diversity within clusters was fairly weak $(0.063 \pm 0.024$ for cluster $1,0.193 \pm 0.059$ for cluster 2 and $0.218 \pm 0.060$ for cluster 3 ). The molecular analysis of variance of accessions indicated that 9 and $91 \%$ of the observed variation was between and within the accessions respectively. This value indicated that the accessions were little distinct from each other, but high variations were observed within them. $F_{\text {st }}$ was very weak $(0.092)$, confirming a very weak distance between accessions $(P=0.002)$. The pairwise average genetic distance was calculated within and between accessions. The mean distance within accession (between individuals of the same accession) was very weak for accession NI076 $(0.055 \pm 0.017)$ compared to others (0.246-0.275). The distances between accessions were identical and were the same order of magnitude as those related to individuals within accessions NI084, NI127 and NI145. Thus, this result confirmed those from FCA and AMOVA. The four accessions could be distinguished in two groups. The first were more diverse with individuals dispersed into three clusters and relatively medium genetic diversity (NI084, NI127 and NI145). The second group was represented by the only accession NI076 for which all individuals fell into cluster P1 with the lowest genetic diversity.

\section{Discussion}

Annealing temperature had a great influence in the optimization of PCR-based genetic markers (Bornet and Branchard, 2001). Some studies used a unique and low annealing temperature $\left(T_{\mathrm{a}}\right)$ for ISSR amplifications with different primers (Sanchez de la Hoz et al., 1996). Some others used primerspecific $T_{\mathrm{a}}$ always higher than $T_{\mathrm{m}}$ (Bornet and Branchard, 2001). In our case, $T_{\mathrm{a}}$ was primer-specific, below or above $T_{\mathrm{m}}$. The three groups of $T_{\mathrm{a}}$ generated could facilitate routine PCR amplification procedure. To obtain a reliable result from genetic analyses, a high number of primers represent an important advantage (Verma et al., 2007; Behera et al., 2008). Twenty ISSR primers are now available to examine edible seeded $C$. lanatus genetic variability. Wang et al. (2005) founded high number of alleles by locus in Chinese watermelon (198 alleles for 8 primers) but only 120 of them showed polymorphism (60.60\%). In the present study, the percent of polymorphic bands (97.67\%) clearly indicated that the ISSR markers are highly polymorphic and especially informative for estimating genetic relationships. High percentage of polymorphism based on ISSR markers was obtained by Paris et al. (2003) in Cucurbita pepo (74\%); Behera et al. (2008) in Momordica charantia and Verma et al. (2007) in Benincasa hispida (>80\%). These studies demonstrated that ISSR markers frequently detected a higher level of polymorphism than that detected with other dominant markers (RAPD or AFLP) among Citrullus or other Cucurbitaceae (Paris et al., 2003; Sensoy et al., 2007; Behera et al., 2008). Stepansky et al. (1999) showed in Cucumis melo L. the same trend i.e. a low polymorphism with RAPD (6.9 bands/alleles and 70\% of polymorphic alleles) than with ISSR ( 9 bands/alleles and $90 \%$ of polymorphic alleles).

The different analyses carried out showed a low level of structure inside accession zone whereas the level of structuring by cluster or profiles was high. Profiles were thus more significant than accessions in term of genetic diversity. The low level of genetic diversity observed in the present study, notably in cluster 1 and particularly in the accession NI076 could be explained in several ways. The genetic basis of the cultivated $C$. lanatus is known to be narrow (Maggs-Kölling et al., 2000; Levi et al., 2004). The accessions used in this study did not escape to previous general conclusions. One hypothesis which could explain the low level of diversity would be the origin of the cultivation. The entire set of accessions of $C$. lanatus could be the resultant of one single entry point and then gradually by migration, the seeds were widespread in the entire country. Similar observations were reported by Romão (2000) from a study related to the evolution of watermelon after its introduction in Northeast Brazil by African slaves. The factors like genetic drift, sampling effect or bottleneck can cause big losses of genetic variation for small populations (Ellstrand and Elam, 1993) like C. lanatus populations dispersed from women stocks and fields in Côte d'Ivoire. Another hypothesis could be attributed to peasant's agricultural practices. Two approaches are currently observed for the treatment of harvested seeds. In one hand, the peasants preserve a part of their harvest for the next sowing, thus, possibly losing part of their diversity at each cultivation period. The less variable accession NI076 could be a result of many self-reproduction of the same seeds stock from several generations. In the second hand, women currently take a part of reserve of their parents or neighbours or at the market in order to establish a new culture or to restore losing seeds of precedent harvests. Thus, it may happen that accessions NI084, NI127 and NI145 for which individuals failed into three clusters and had medium genetic diversity resulted from frequent seeds exchange between women.

\section{Conclusion and perspective}

For underutilized species like edible seeded C. lanatus, the optimization of any new technology could be powerful for management. The ISSR marker system was quick and highly reproducible. It generated sufficient polymorphism to have largescale DNA fingerprinting purposes. This study enabled us to find twenty ISSR primers, which could be used directly for the further molecular studies on this species.

The genetic structure observed was characterised by three clusters that did not correspond to accessions analysed. To confirm such a pattern and then use reliability the results for genetic resources collection and management purposes, further investigation using more accessions are needed.

\section{Acknowledgments}

This research was financed by the Direction Générale de la Coopération au Développement (DGCD, Brussels, Belgium) and supervised by the Comité Interuniversitaire pour le Développement (CUD, Brussels, Belgium). Thank to Willy Dussard for his technical assistance.

\section{References}

Badifu, G.I.O., 2001. Effect of processing on proximate composition, antinutritional and toxic contents of kernels from Cucurbitaceae species grown in Nigeria. J. Food Comp. Anal. 14, 153-161. 
Behera, T.K., Singh, A.K., Staub, J.E., 2008. Comparative analysis of genetic diversity in Indian bitter gourd (Momordica charantia L.) using RAPD and ISSR markers for developing crop improvement strategies. Sci. Horticult. 115, 209-217.

Bornet, B., Branchard, M., 2001. Nonanchored intersimple sequence repeat (ISSR) markers: reproducible and specifics tools for genome fingerprinting. Plant Mol. Biol. Rep. 19, 209-215.

Djè, Y., Tahi, G.C., Zoro Bi, I.A., Malice, M., Baudoin, J.P., Bertin, P., 2006. Optimization of ISSR markers for African edible-seeded Cucurbitaceae species' genetic diversity analysis. Afr. J. Biotechnol. 5, 83-87.

Ellstrand, N.C., Elam, B.R., 1993. Population genetic consequences of small population size: implications for plant conservation. Ann. Rev. Ecol. Syst. 24, 217-242.

Ellul, P., Lelivelt, C., Naval, M.M., Noguera, F.J., Sanchez, S., Atarés, A., Moreno, V. Corella, P., Dirks, R., 2007. Watermelon Biotechnol. Agric. Forest 60, 129-165.

Ferreira, M.A.J., Vencovsky, d., Vieira, R., de Queiróz, M.L.C.,M.A., 2008. Outcrossing rate and implications for the improvement of a segregating population of watermelon. VII Eucarpia Meeting on Cucurbit Genetics and Breeding. Acta Horticult. 510, 47-54

Jaskani, M.J., Kwong, S.W., Kim, D.H., 2005. Comparative study on vegetative, reproductive and qualitative traits of seven diploid and tetraploid watermelon lines. Euphytica 145, 259-265.

Katzir, N., Danin-Poleg, Y., Tzuri, G., Karchi, Z., Lavi, U., Cregan, P.B., 1996. Length polymorphism and homologies of microsatellites in several Cucurbitaceae species. Theor. Appl. Genet. 93, 1282-1290.

Levi, A., Thomas, C.E., Newman, N., Reddy, O.U.K., Zhang, X., Xu, Y., 2004. ISSR and AFLP markers differ among American watermelon cultivars with limited genetic diversity. J. Am. Soc. Hortic. Sci. 129, 553-558.

Maggs-Kölling, L.G., Madsen, S., Christiansen, L.J., 2000. A phenetic analysis of morphological variation in Citrullus lanatus in Namibia. Genet. Resour. Crop Evol. 47, 385-393.

McGregor, C.E., Lambert, C.A., Greyling, M.M., Louw, J.H., Warnich, L., 2000. A comparative assessment of DNA fingerprinting techniques (RAPD, ISSR, AFLP and SSR) in tetraploid potato (Solanum tuberosum). Euphytica 113, 135-144.

Murray, M.G., Thompson, W.F., 1980. Rapid isolation of high molecular weight plant DNA. Nucleic Acids Res. 10, 4321-4325.

Nei, M., Li, W.H., 1979. Mathematical model for studying genetic variation in terms of restriction endonucleases. Proc. Natl. Acad. Sci. U.S.A. 76, 5269-5273.

Paris, H.S., Yonash, N., Portnoy, V., 2003. Assessment of genetic relationships in Cucurbita pepo (Cucurbitaceae) using DNA markers. Theor. Appl. Genet. 106, 971-978.
Peakall, R., Smouse, P.E., 2006. GenAlEx 6: genetic analysis in Excel, Population genetic software for teaching and research. Mol. Ecol. Notes 6, 288-295.

Pejic, I., Ajmone-Marsan, P., Morgante, M., Kozumplick, V., Castiglioni, P., Taramino, G., Moto, M., 1998. Comparative analysis of genetic similarity among maize inbred lines detected by FFLPs, RAPD, SSRs and AFLPs. Theor. Appl. Genet. 97 1248-1255.

Romão, R.L., 2000. Northeast Brazil: a secondary centre of diversity for watermelon (Citrullus lanatus). Genet. Res. Crop Evol. 47, 207-213.

Russell, J., Fuller, J., Young, G., Thomas, B., Taramino, G., McCauley, M., Waugh, R. Powell, W., 1997. Discriminating between barley genotypes using microsatellite markers. Genome 40, 442-450.

Sanchez de la Hoz, M.F, Dàvila, J.A., Loarce, Y., Ferrer, E., 1996. Simple sequence repeat primers used in polymerase chain reaction amplifications to study genetic diversity in barley. Genome 39, 112-117.

Sensoy, S., Büyükalaca, S., Abak, K., 2007. Evaluation of genetic diversity in Turkish melons (Cucumis melo L.) based on phenotypic characters and RAPD markers. Genet. Resour. Crop Evol. 54, 351-365.

Stepansky, A., Kovalski, I., Perl-Treves, R., 1999. Intraspecific classification of melons (Cucumis melo L.) in view of their phenotypic and molecular variation. Plant Syst. Evol. 217, 313-332.

Van de Peer, Y., De wachter, R., 1994. TREECON for windows: a software package for the construction and drawing of evolutionary trees for the Microsoft windows environment. Comp. Appl. Biosc. 10, 569-570.

Verma, V.K., Behera, T.K., Munshi, A.D., Parida, S.K., Mohapatra, T., 2007. Genetic diversity of ash gourd [Benincasa hispida (Thunb.) Cogn.] inbred lines based on RAPD and ISSR markers and their hybrid performance. Sci. Horticult. 113, 231237.

Wang, J.Y., Chang, Y.M., Shen, B.K., Wang, Y.H., Liou, P.C., 2005. Molecular markers derived from RAPD and ISSR analysis for identification of watermelon. J. Taiwan Agric. Res. 54, 257-269.

Zietkiewicz, E., Rafalski, A., Labuda, D., 1994. Genome fingerprinting by simple sequence repeat (SSR)-anchored polymerase chain reaction amplification. Genomics 20, 176-183.

Zoro Bi, I.A., Koffi, K.K., Djè, Y., 2003. Caractérisation botanique et agronomique de trois espèces de cucurbites consommées en sauce en Afrique de l'ouest, Citrullus sp., Cucumeropsis mannii Naudin, Lagenaria siceraria (Molina) Standley. Biotechnol. Agron. Soc. Env. 7, 189-199.

Zoro Bi, I.A., Koffi, K.K., Djè, Y., Malice, M., Baudoin, P., 2006. Indigenous cucurbits of Côte d'Ivoire: a review of their genetic resources. Sci. Nat. 3, 1-9. 